\title{
Las fuentes informativas en el periodismo de sucesos. Análisis en la prensa escrita
}

\author{
Recibido: 01 de octubre de 2015 \\ Aceptado: 25 de mayo de 2016 \\ Publicado: 30 de noviembre de 2016
}

\author{
Rosa María Rodríguez Carcela \\ rmaria.rodriguez@juntadeandalucia.es \\ Universidad de Sevilla (España)
}

\begin{abstract}
Resumen: Este artículo se ha centrado en el uso que la prensa escrita hace de las fuentes informativas en el periodismo de sucesos ${ }^{1}$. Las fuentes oficiales y las de agencias son las que tienen mayor presencia en los diarios analizados. La policial es la fuente oficial especializada más importante y es EFE la agencia más citada por los periodistas. Las fuentes no oficiales que más utilizan los reporteros con las reservadas o confidenciales (se suelen citar genéricamente como "según las fuentes consultadas"), las familiares y las vecinales. Las fuentes fotográficas adquieren cada vez mayor relevancia en los sucesos y proceden mayoritariamente de los fotógrafos de las propias redacciones y de las agencias. Los reporteros emplean un elevado número de fuentes atribuidas, pero insuficientemente identificadas.
\end{abstract}

Palabras clave: Fuentes informativas, periodismo de sucesos, prensa escrita.

Abstract: This article is focused on the use of the news sources by Print Media in incident \& crime reports. Official sources and agencies have a greater presence in analyzed newspapers. The Police is the major official and specialized source, and EFE Agency is the mostly quoted by journalists. The unofficial sources more often used by reporters are, in first place, the unidentified or confidential sources (commonly quoted generically as "according to consulted sources") following the family and neighborhood sources.

1 La información de sucesos es conocida en países como Perú o México con los términos de "nota policial", "nota roja" o "crónica roja". 
Graphic sources are becoming increasingly important in crime \& incident reports and come mostly from photographers working for the newspapers and agencies. Reporters employ a large number of sources inadequately identified.

Key words: News Sources, Accident \& Crime Reports, Print Media.

\section{Introducción}

La fuente no es sólo el origen de la información y el aval de su fiabilidad, sino que se convierte en el eje del relato periodístico. Los sucesos son una especialidad periodística centrada en informaciones sobre delincuencia, siniestros, catástrofes y hechos curiosos y sorprendentes. Los reporteros especializados en sucesos (la nota roja) utilizan sus propias fuentes, pero dependen cada vez más de otras de carácter oficial o institucional, siendo la más consultada la policial.

A través de este artículo se pretende hacer una aportación teórica sobre las características del periodismo de sucesos (la nota roja) en la prensa escrita, centradas en el uso de las fuentes informativas. El estudio hace un análisis de la tipología y la procedencia de las fuentes con las que trabaja el periodista, así como sobre la identificación o atribución que hacen de ellas en sus textos, aunque también se abordarán las fotografías.

Las fuentes que utiliza el periodista para elaborar las informaciones de sucesos son muy variadas: policiales, judiciales, sanitarias, gubernamentales, vecinales, testigos directos, confidentes, autores, víctimas, familiares, etcétera. Ello se debe a que la temática de sucesos es muy amplia y va más allá de la comisión de los delitos. La credibilidad y el rigor de un medio de comunicación están en relación directa con sus fuentes.

Según se trate de un reportero especializado (o no) en sucesos, la dinámica de trabajo será diferente, ya que el especialista tratará de buscar (siempre que pueda) fuentes propias frente a las oficiales y algunas de ellas las tendrá que citar de forma reservada o confidencial para preservar el anonimato de sus informantes y el secreto profesional ${ }^{2}$. El periodista generalista, que hace un poco de todo, depende más de las fuentes de agencias y oficiales y atribuye (o no) la fuente, según le venga dada o del espacio que disponga para redactarla y titularla.

La especialización en este tipo de información es fundamental, puesto que los periodistas expertos en sucesos disponen de sus propias fuentes que hacen que sus trabajos se diferencien del resto, ganando en objetividad al contrastar las versiones oficiales. La pobreza de las fuentes y la falta de datos precisos pueden favorecer la especulación, ya que el rigor se consigue a través del contraste.

2 La defensa de la intimidad de la fuente se fundamenta en los principios éticos y deontológicos que sustenta la actividad profesional del periodista. 
Cada fuente difunde una versión de la realidad. Por ello el buen periodismo de sucesos es igual al uso de fuentes propias, rigurosas y variadas. La fuente es básica y define no sólo al profesional, sino al medio de comunicación para el que trabaja o colabora, ya que mientras mejores fuentes dispongan, mejor excelencia informativa. En cualquier caso, estos planteamientos teóricos a tener en cuenta chocan en muchas ocasiones con la realidad de la dinámica periodística, sometida a las presiones del poder y a la insuficiencia de recursos económicos y humanos en los periódicos.

\section{Metodología}

Los datos que se recogen en este artículo se han elaborado tomando como referencia la tesis doctoral titulada La información de sucesos en la prensa sevillana (2009), donde se analizan las fuentes citadas, o no, en más de 3500 noticias publicadas en los diarios $A B C$ de Sevilla, Diario 16 Andalucía y El Correo de Andalucía ${ }^{3}$ (figura 1).

Figura 1: Frecuencia de aparición de las fuentes informativas (noticias).

\begin{tabular}{|l|c|}
\hline Agencias & $\mathbf{3 2 . 5 0 \%}$ \\
\hline Oficiales & \\
Tipo de fuentes citadas: & $29.88 \%$ \\
- Policiales & \\
- Justitucionales & \\
\hline Indeterminades & $\mathbf{2 7 . 8 2 \%}$ \\
No constan & \\
\hline No oficiales & \\
\hline Tipo de fuentes citadas: & \\
\hline - Propias & \\
\hline - Protagonistas & \\
\hline
\end{tabular}

Fuente: Rodríguez (2009).

3 La autora ha analizado un total de 3526 registros informativos (noticias de sucesos) y consultado 546 ejemplares de los tres diarios locales citados, tomando como referencia el año 1995. 
Asimismo, se ha realizado otro análisis de fuentes más actual (que hemos denominado, para diferenciarlo del anterior, "estudio 2016") proveniente de los periódicos $A B C$ de Sevilla, Diario de Sevilla, El Correo de Andalucía, El Mundo (edición Andalucía) y El País, desde el viernes 6 al domingo 15 de mayo (figura 2). Se han computado 263 registros informativos (158 noticias y 105 fotografías) que suman un total de 315 fuentes, de las cuales 210 son textuales (informaciones) y 105 gráficas (fotos). Aclaramos que en las 158 noticias de sucesos (publicadas en los cinco diarios) se registran 210 fuentes informativas, puesto que aquellas (en ocasiones) citan a más de una fuente.

Figura 2: Frecuencia de aparición de las fuentes informativas (noticias y fotos).

\begin{tabular}{|c|c|}
\hline $\begin{array}{l}\text { Oficiales } \\
\text { Tipo de fuentes citadas: } \\
\text { - Institucionales } \\
\text { - Policiales (noticias + fotos) } \\
\text { - Judiciales }\end{array}$ & $32.06 \%$ \\
\hline $\begin{array}{l}\text { No oficiales } \\
\text { Tipo de fuentes citadas: } \\
\text { - Propias (noticias + fotos) } \\
\text { - Protagonistas } \\
\text { - Otros medios de comunicación } \\
\text { (noticias + fotos) }\end{array}$ & $32.38 \%$ \\
\hline $\begin{array}{l}\text { Agencias } \\
\text { Tipo de fuentes utilizadas: } \\
\text { - Fotos } \\
\text { - Noticias }\end{array}$ & $26.66 \%^{1}$ \\
\hline $\begin{array}{l}\text { Indeterminadas } \\
\text { No constan }\end{array}$ & $8.8 \%$ \\
\hline
\end{tabular}

Fuente: Elaboración propia.

Aunque el periodo analizado en el estudio 2016 no es amplio, en los 50 ejemplares consultados de los periódicos citados sí se ofrecen datos orientativos de interés que vienen a complementar los resultados obtenidos en la tesis y además permiten observar el comportamiento o tendencias en la prensa escrita española de 2016. La aportación más novedosa que se realiza es el tratamiento de las fotos, ya que la tesis no contempla este tipo de fuente informativa al estar centrada exclusivamente en las noticias. Por tanto, en los porcentajes comparativos que se hacen de ambos trabajos, tomamos como referencia las 
fuentes textuales que se citan en las noticias. Además, se muestran los datos porcentuales que ofrece este estudio en su conjunto, sumando ambas fuentes (informaciones y fotos) y de forma específica en las fotografías.

Los datos obtenidos en los dos trabajos mencionados, que se toman como guía, nos han permitido hacer un estudio aproximativo sobre el uso periodístico de las fuentes de información en la prensa escrita. Para ello, se ha analizado la tipología, la procedencia de las fuentes con las que trabaja el periodista (atendiendo al criterio de la oficialidad o no de la fuente) y su atribución (cómo las citan o identifican en sus textos), estableciendo la siguiente clasificación genérica: oficiales, no oficiales, agencias e indeterminadas (no se citan).

El resto de datos que documentan y complementan este trabajo se han obtenido a través de la recopilación de fuentes orales (entrevistas realizadas a periodistas especializados en sucesos) y bibliográficas.

\section{Fuentes oficiales}

Provienen de la autoridad del Estado o de una institución. Puede tratarse de un organismo gubernamental o autoridad administrativa (estatal, regional o local) o bien de una institución pública o privada (empresarial, sindical, asociaciones profesionales) y se expresan en representación de ambas. Habitualmente difunden sus actuaciones a través de comunicados de prensa, portavoces autorizados y ruedas de prensa.

Estas fuentes también atienden a los medios en sus demandas informativas, tanto para confirmar, desmentir o ampliar datos y suelen acudir a los periodistas especializados cuando tratan de difundir o "vender" determinados temas que a la propia institución le interesa. Las autoridades (con vistas a controlar la información que se suministra a los medios y a disponer de un canal oficial de comunicación) cuentan cada vez más con sus gabinetes de prensa que filtran los datos oficiales a su favor.

Se trata de fuentes muy amplias, jerarquizadas (estructuras de poder burocratizado) y variadas. Para simplificar hemos hecho una clasificación que engloba a las institucionales (las más extensas), las policiales (las más especializadas) y las judiciales (las menos citadas).

La presencia de este tipo de fuentes es cada vez mayor en las noticias de sucesos que se publican en la prensa escrita, analizada sobre todo las institucionales que veremos a continuación. Los datos recabados, a través de la tesis y del estudio 2016, reflejan que las fuentes oficiales son citadas con mayor frecuencia que las no oficiales. Hay, por tanto, en el periodismo de sucesos una prevalencia de la fuente secundaria (mediatizada) sobre la primaria (de primera mano). 


\subsection{Fuentes institucionales}

Son las fuentes "que son o pertenecen a instituciones públicas o privadas definidas e identificables y hablan en representación o en calidad de ambas" (Diezhandino y Coca, 1997: 54). Se trata de fuentes oficiales, ya que representan a un gobierno, administración, empresa o agrupación profesional determinada: partidos políticos, asociaciones, hospitales, sindicatos, autoridades ministeriales, regionales o municipales...

Este tipo de fuente es muy representativa en el periodismo de sucesos, ya que es frecuentemente citada en los periódicos analizados. Emana de los organismos gubernamentales (ministeriales ${ }^{4}$, regionales y municipales), así como de otras instituciones (hospitalarias, emergencias 112, portavoces oficiales y comunicados de empresas, asociaciones profesionales, partidos políticos o sindicatos) y de otras indeterminadas ("Fuentes consultadas por este periódico...")

\subsection{Fuentes policiales}

La Policía es la fuente oficial especializada más importante del periodismo de sucesos. Suministra notas de prensa y fotografías. Sus informaciones se canalizan a través de los gabinetes de prensa y portavoces. Hemos agrupado en esta categoría las provenientes del Cuerpo Nacional de Policía, Guardia Civil y otros cuerpos (policía local y autonómica) existentes en España.

Debido a la relevancia de la fuente policial (y al estar diferenciada del resto de las oficiales por su especialización en temas de delincuencia) no la hemos incluido dentro de las institucionales, aunque la policía dependa genéricamente de una autoridad gubernativa.

A nivel extraoficial o particular los agentes y cuerpos de Seguridad del Estado no suelen facilitar información, ya que les está prohibido, debiendo contar con autorización oficial o de un superior jerárquico. No obstante, los periodistas suelen disponer de contactos policiales que, de manera extraoficial, facilitan datos e informaciones relevantes sobre un determinado caso.

Los periodistas especializados y los portavoces policiales consultados también manifiestan la transcendencia de este tipo de fuente. Ello es debido a que la Policía es una de las fuentes que tiene un conocimiento más inmediato del escenario del suceso. En opinión de Quesada (2007: 133) "las más importantes fuentes oficiales de la información sobre sucesos se localizan dentro del ámbito policial”. Ronda y Calero (2000: 67) consideran que la policía es una fuente de alcance, aunque "constituye siempre la versión oficial” y suele realizar notas informativas "cuando el suceso ha pasado".

4 Fundamentalmente se canaliza la información a través del Ministerio del Interior. El Ministerio de Defensa es más minoritario como fuente del periodismo de sucesos, no así en el periodismo judicial. El Ministerio del Interior español es competente en terrorismo y crimen organizado y de este dependen, entre otros organismos, la Dirección General de la Policía, la Dirección General de la Guardia Civil, Instituciones Penitenciarias, Extranjería, Política Interior y Dirección General de Tráfico. 
Para Fernando Pérez Ávila (2014) las fuentes policiales "son relevantes, pero difíciles de conseguir sobre todo si no son oficiales". Como premisa a tener en cuenta señala que cuantas más fuentes dispongas es mejor para elaborar una información de sucesos de calidad. No sólo es necesario contar con la versión policial, sino con las de todas las partes afectadas en los hechos. Ballesteros (2008) comenta que este tipo de fuente transmite una interpretación oficial de los hechos:

"Las fuentes principales son los testigos directos de los sucesos. Las fuentes oficiales, como son las policiales, son lentas y siempre están bajo el secreto sumarial. Otra cosa es que tengas amigos dentro de la policía y te puedan facilitar datos interesantes".

En esta línea, Juan Carlos Arias (2014) apostilla que las fuentes más codiciadas por el reportero son las de los testigos y las personas que conocen a la víctima:

"La Policía no es la fuente más importante, sino el testigo del suceso que ha presenciado el crimen o el acto delictivo. Se convierte en fuente cuando está en el proceso de investigación, pero en la fase inicial del delito no lo es".

La portavoz del Gabinete de Prensa de la Jefatura Superior Policía Nacional de Andalucía Occidental $^{5}$, Ana Cambón (2008), estima que este tipo de fuente es fundamental, debido a su credibilidad y a que los policías son los perceptores de la delincuencia que luego transciende a los periodistas:

"Damos la credibilidad y poseemos de primera mano la información. Los medios acuden a nosotros porque somos los que tenemos la denuncia y los datos de los hechos. Los testigos y las víctimas en ocasiones no tienen esa misma credibilidad y por ello los medios necesitan la base fiable que se la facilita la Policía".

El peso de la fuente policial también ha aumentado con la creación de sus propios gabinetes de prensa, canales oficiales de comunicación, los cuales han facilitado a los periodistas un acceso a la información más normalizado y menos dificultoso. Actualmente, las comisarías de Policía en España no están autorizadas a suministrar información a los medios, ya que los órganos de comunicación oficiales son los gabinetes de prensa. El Ministerio del Interior creó en 2013 una Oficina de Prensa y Relaciones Informativas, encargada de planificar, preparar, coordinar y realizar las comunicaciones y relaciones de los órganos directivos del Cuerpo Nacional de Policía con los medios de comunicación social, de la que dependen todos los gabinetes de prensa de la Policía Nacional.

5 La Jefatura Superior de Policía de Andalucía Occidental, con sede en Sevilla, tiene como ámbito de actuación las provincias andaluzas de Sevilla, Cádiz, Córdoba y Huelva (España). 
Las Jefaturas Superiores de Policía cuentan con gabinetes de prensa cuyas funciones son las de servir de punto de conexión entre la Policía Nacional y los medios de comunicación, difundir los servicios policiales más relevantes, confirmar o desmentir aquellas noticias de las que se informan por sus propias fuentes los periodistas, la difusión de notas de prensa o ruedas de prensa. La Dirección General de la Policía cuenta con cuenta propia en la red social Twitter (@policia) que gestiona desde el 2009, en la que se informa de las operaciones que desarrolla. Las demandas informativas más frecuentes por parte de los medios de comunicación al gabinete de prensa de la Policía Nacional son aquellas sobre las actuaciones de este cuerpo, especialmente las referidas a los delitos sexuales, los asesinatos, los delitos tecnológicos y las noticias en las que las víctimas son menores de edad.

Asimismo, incluimos como fuente policial destacada a la Guardia Civil, instituto armado de naturaleza militar que cuenta con gabinetes de prensa (se denominan oficialmente Oficinas Periféricas de Comunicación, $\mathrm{OPC}^{6}$ ). El representante de la OPC de Sevilla (2014) considera que las fuentes de los Cuerpos y Fuerzas de Seguridad del Estado (policiales) son una de las más habituales e importantes del periodismo de sucesos por su "objetividad y fiabilidad de los datos". Asimismo explica que difunden notas de prensa cuando la información

\begin{abstract}
"se considera de utilidad social y atendemos a los medios cuando estos demandan datos de temas que atañen al trabajo y la imagen del cuerpo, o confirman informaciones que los reporteros obtienen en su trabajo por vías externas a la institución y atañen a la misma. Destacan por su interés informativo los sucesos de carácter trágico, tanto los accidentes como los crímenes, ya que suscitan gran demanda sobre las actuaciones que se practican en tales hechos".
\end{abstract}

\title{
3.3. Contrastar y ampliar las fuentes policiales
}

A pesar de la importancia de las fuentes policiales, los periodistas que cubren sucesos no deben limitarse a elaborar sus informaciones con las notas de prensa policiales (que habitualmente esconden lo que no les favorece), sino que tienen que profundizar y acudir a más fuentes. Un mal uso detectado, que siempre hay que evitar, es cuando el periodista firma una información, cuyo contenido redaccional es básicamente el mismo que el emitido por el comunicado de prensa de la Policía.

Además las relaciones Prensa-Policía son a veces conflictivas, debido a la propia naturaleza del trabajo de ambas profesiones, donde el periodista tiene la obligación de informar y el

6 La Guardia Civil es un Cuerpo de Seguridad Pública y de ámbito nacional que forma parte de las Fuerzas y Cuerpos de Seguridad del Estado de España. Su origen se remonta al 28 de marzo de 1844. Depende del Ministerio del Interior en cuanto a servicios, retribuciones, destinos y medios, y del Ministerio de Defensa en cuanto a ascensos y misiones de carácter militar. Además, atiende las necesidades del Ministerio de Hacienda relativas al Resguardo Fiscal del Estado, y vela por el cumplimiento de las normas y reglamentos relacionados con los diferentes órganos de la Administración Central, la Autonómica y la Local. 
policía de investigar y ser discreto. También hay que tener presente que los comunicados policiales ofrecen una información muy resumida y a veces censurada, en aras de proteger las investigaciones policiales en curso.

La Guardia Civil, por ejemplo, tiene como norma general divulgar oficialmente las notas de prensa "cuando la investigación o las actuaciones sobre el hecho se dan por finalizadas", según explica su portavoz oficial (2014). Es decir, no cuando se producen los hechos delictivos, la noticia, sino a posteriori. Asimismo, estos portavoces tienen especial cuidado con las víctimas, ya que pueden ser fácilmente identificadas cuando viven en núcleos de población pequeños y también con las investigaciones en curso. Como vemos, la práctica habitual es que cuando ocurre un suceso actúen a continuación los cuerpos policiales. Ello significa que mientras la investigación policial esté en marcha va a ser muy complicado para el periodista acceder a la información que le permita la explicación del hecho delictivo.

En opinión de los periodistas de sucesos consultados, la información que proviene de los gabinetes de prensa policiales está controlada, ya que ofrecen la versión de la institución, eludiendo detalles que les pueda perjudicar. Así lo explica Pérez Ávila (2014):

"Cuando recibo comunicados de la policía tengo presente que los datos que se ofrecen están mediatizados. Una nota de prensa te informa, por ejemplo, de que se han detenido a dos narcotraficantes, pero no te dice que se han escapado otros dos. Ese dato lo tienes que buscar por otro lado, con el fin de ofrecer una información de calidad, lo más cercana a la realidad de los hechos".

El reportero Chema Rodríguez (2014) aclara que las mayores dificultades con las que se encuentra el periodista de sucesos son las que, a nivel institucional, ponen tanto los cuerpos de seguridad como la Administración de Justicia para intentar que la información relativa a un suceso no se difunda:

"Al menos no hasta que sus responsables lo decidan y cómo ellos lo decidan. Los gabinetes de prensa son en muchas ocasiones filtros que no dejan pasar la información y excusas para perseguir a todo aquel que dé información al margen de los mismos".

En este línea, Pérez Ávila (2014) subraya la complejidad que supone "tratar con gente que no está dispuesta a contarte cosas" más allá de la versión oficial, como ocurre en los gabinetes de prensa de los cuerpos de seguridad. En el caso de los miembros de la Guardia Civil que se atreven a filtrar información a los medios pueden ser sancionados, al ser un cuerpo militarizado.

El argumento que suele utilizar la Policía para justificar esta falta de transparencia es que dar datos a la prensa (mientras se está realizando una investigación policial) implica facilitar pistas a los presuntos autores de los hechos delictivos ("los malos", en lenguaje policial) y, en consecuencia, precipitar el fracaso de dicha investigación. En este sentido, los portavoces aclaran que lo más importante es la investigación policial, por este motivo 
se intenta retener la información. Así lo manifiesta la jefa de Prensa de la Policía Nacional en Andalucía Occidental (2008):

"La nota de prensa no la solemos difundir cuando han acontecido los hechos delictivos, a no ser que sea un tema que ha transcendido y tenemos que ofrecer algunas aclaraciones públicas. En ocasiones, llegamos a acuerdos con los periodistas cuando se han enterado antes de que nosotros difundamos los sucesos. La norma es que no podemos informar si con ello perjudicamos a la investigación, por ello facilitamos la nota dos o tres días después de acontecidos los hechos".

Por su parte el periodista Heriberto Ochoa explica el funcionamiento en México, donde en los casos del día a día es más fácil consultar fuentes policiales y disponer de un comunicado o nota de prensa, ya que funcionan las denominadas áreas de Comunicación Social (los Gabinetes de Prensa) que atienden las peticiones de los reporteros, bien sea para ampliar la información de un hecho o darle seguimiento al mismo:

\begin{abstract}
"Pongamos por caso una persona asesinada en la vía pública: se acude al lugar, donde se recaban los datos a través de varias entrevistas, con los oficiales de la Policía Preventiva que estén en el lugar y, a ser posible, con los de la de Investigación (estos dependen de la Procuraduría General de Justicia de la Ciudad de Méjico, que es el equivalente a la Fiscalía en España); si hay tiempo puede acudirse al Servicio Médico Forense (Semefo) para que uno de los peritos den un adelanto de lo que encontraron en el cuerpo o esperamos hasta el siguiente día para que la información esté más sólida”.
\end{abstract}

En el caso de detenciones relevantes, avances de una investigación o un caso mediático, las autoridades policiales mexicanas convocan a los periodistas a conferencias de prensa, las cuales se aprovechan para obtener información de otros casos que cada reportero traiga en su agenda o requieran de seguimiento. En el caso español es similar, ya que ante sucesos de gran impacto social se convoca a los periodistas a ruedas de prensa que ofrece el propio ministro del Interior ${ }^{7}$.

En definitiva, el acceso a las fuentes policiales pone de manifiesto uno de los aspectos más difíciles del ejercicio profesional, como es la fina barrera que separa las investigaciones de los periodistas con las propias la Policía.

7 Hacemos mención al caso del "Pederasta de Ciudad Lineal", en Madrid, España que despertó gran alarma social entre los ciudadanos. El 24 de septiembre de 2014 fue detenido por la Policía en Santander Antonio Ortiz Martínez, el presunto autor de las agresiones sexuales a cinco niñas cometidas en la zona madrileña de Ciudad Lineal. Durante más de un año el considerado por la Policía "El enemigo público número 1 de Madrid”, generó una intensa investigación policial que finalizó con su captura. El ministro del Interior ofreció una rueda de prensa informando sobre la captura del "delincuente más buscado de España". Al día siguiente, este asunto se convirtió en la noticia más destacada de la prensa escrita. 


\subsection{Judiciales}

Se refieren a todas aquellas fuentes de la Administración de Justicia (jueces, magistrados, secretarios judiciales, fiscales y letrados). No se incluyen a los abogados privados que defienden a las partes afectadas y se consideran fuentes no oficiales. Detectamos que esta fuente oficial es menos representativa que la policial en el periodismo de sucesos, aunque sí adquiere mayor importancia en el periodismo judicial, especialidad que no es objeto de este artículo.

Los periodistas especializados en sucesos suelen cubrir posteriormente información judicial relativa a los delitos cometidos. Es usual que el periodista de sucesos lo sea también de tribunales, especialmente en el ámbito penal. Estos profesionales son asiduos visitantes de los juzgados, ya que son lugares imprescindibles para conseguir noticias sobre un caso determinado en su fase de proceso judicial. Nos referimos a las fuentes de los diferentes órganos y funcionarios pertenecientes a la Administración de Justicia, como son los juzgados, las audiencias provinciales y los tribunales. También se incluyen a los médicos forenses que son funcionarios de carrera que constituyen un Cuerpo Nacional de Titulados Superiores al servicio de la Administración de Justicia ${ }^{8}$.

Junto a las fuentes judiciales personales están las documentales, es decir, las resoluciones judiciales (providencias, autos y sentencias) y el escrito de calificación provisional de los hechos. La tesis doctoral constató que la sentencia es la fuente judicial que con mayor frecuencia utiliza la prensa analizada. Es habitualmente citada en los diarios, por su carácter oficial y público, ya que se refiere a la decisión del juez sobre un hecho delictivo concreto. Es, por tanto, la resolución judicial que pone fin al proceso judicial o a la causa penal.

El acceso a las fuentes judiciales está sometido a restricciones, tanto marcadas por la ley como por las propias autoridades judiciales que son poco accesibles (por ejemplo, los jueces). El secreto del sumario en España es uno de los límites más importantes que encuentra el periodista en la fuente judicial ${ }^{9}$. No obstante, existen las filtraciones interesadas en los órganos jurisdiccionales que pueden ayudar al periodista a proporcionarle una exclusiva o bien a profundizar en una determinada investigación que realiza sobre un caso concreto. De ahí la importancia de saber buscar fuentes alternativas y contrastar las versiones interesadas de un determinado caso o proceso.

8 En España los denominados Institutos de Medicina Legal y Ciencias Forenses son órganos técnicos adscritos al Ministerio de Justicia o, en su caso, a gobiernos regionales con competencia en la materia, cuya misión principal es auxiliar a la Administración de Justicia en el ámbito de su disciplina científica y técnica.

9 El sumario forma parte de la primera fase del proceso penal que trata de averiguar el delito de que se trate y su autor o persona presuntamente responsable, recogiendo todos los datos disponibles de la investigación. 


\section{Fuentes no oficiales}

Son aquellas en las que no media un intermediario oficial para acceder a la información. Por tanto, no tienen su origen en una institución o autoridad gubernamental. No representan los intereses de un gobierno o una institución, sino los de las personas afectadas (directa o indirectamente) por los sucesos. Son los contactos propios que tienen y se trabajan los reporteros especializados. Comprenden tanto los testimonios directos o las fuentes primarias (autores, víctimas, testigos presenciales o policías que suministran datos de manera extraoficial), como las informaciones obtenidas de personas próximas a los protagonistas de los sucesos (familiares, amigos, conocidos o vecinos). También se incluyen los datos recabados de la observación directa (el periodista acude al lugar de los hechos $\mathrm{y}$, a través de la comprobación e investigación, extrae información que complementa la principal) y las versiones de expertos.

Son fuentes más minoritarias que las oficiales, puesto que tienen menor presencia en las noticias de sucesos publicadas en los periódicos analizados. Es más frecuente que el periodista cite en sus textos una fuente oficial que una no oficial. Pese a esta dinámica de trabajo, los contactos o las fuentes propias son el "verdadero tesoro" de los periodistas de sucesos como así lo avalan los propios reporteros entrevistados. En opinión de Pérez Ávila (2014) son las oficiosas las fuentes más ricas y menos mediatizadas:

"Disponer de estos contactos es un trabajo de años. Proceden de sindicatos policiales, de antiguos grupos de homicidios, tribunales, abogados e incluso de taxistas".

En la misma línea, Casimiro Fernández Muñoz (2014) explica que "las mejores fuentes son las extraoficiales que provienen de los abogados o de fuentes policiales no autorizadas que quieren que la gente se entere de una determinada información que oficialmente se oculta o porque les interesa destapar algunos casos que no salen a la luz pública".

Los denominados “confidentes" también son una de las fuentes no oficiales más importantes del periodismo de sucesos en particular y del periodismo de investigación en general. Son personas que, bajo anonimato, suministran a los periodistas datos de alto valor informativo, ya que suelen trabajar o han trabajado dentro de los organismos oficiales. Como ejemplo, señalamos la investigación periodística realizada por Sebastián Torres y Antonio Salvador para el diario El Mundo sobre el "caso ERE", uno de los mayores hechos de corrupción política cometidos en la historia reciente de España. Ambos periodistas se valieron de "el Rey de los Persas", un nombre en clave, una fuente conectada con las altas instancias de la Junta de Andalucía que a finales de 2010 colaboró con el citado periódico en su investigación ${ }^{10}$. "Su aportación fue determinante y su verdadera identidad sólo la conocen los autores de este libro" (Torres y Salvador, 2015: 25).

10 La Junta de Andalucía es la institución en la que se organiza políticamente el autogobierno de esta región española situada al Sur. Está integrada por el Parlamento de Andalucía, la Presidencia de la Junta y el Consejo de Gobierno. 
La filtración de fuentes "no oficiales" es compleja, ya que requiere dedicación y ganarse la confianza de los informantes. Ochoa Tirado (2016) expone cómo se consigue información extraoficial:

"Si como reportero uno estrecha la relación con los funcionarios, sobre todo de los fiscales, estos pasan datos 'off the record' de cómo va la investigación, o alguno de los agentes investigadores, ya sea el comandante de grupo o de uno de los subordinados, e incluso en las áreas de Comunicación Social -los Gabinetes de Comunicación- proporcionan información no oficial".

Las fuentes no oficiales pueden ser muy diversas y variadas y los recursos para conseguirlas de lo más variopinto. Es una labor casi detectivesca. Una de las prácticas extendidas para conseguir información no oficial es la filtración de datos, fotografías o documentos de las investigaciones en curso. En México, por ejemplo, hasta el año 2004 era común que los periodistas llevaran radios con frecuencias de la Policía y los cuerpos de salvamento que conseguían en el mercado negro. Incluso se formaban grupos de reporteros que estaban en frecuencia y buscaban cómo obtener la información, sobre todo para alimentar sus portales con textos, foto y vídeo. No obstante, a partir de 2005, según Ochoa (2016),

"ninguna de las corporaciones (instituciones) permite que los periodistas traigan radios y a quien los ven con ellas les quitan sus equipos. El no traer esa herramienta de trabajo tampoco impide que realicen su labor porque ahora gracias a Internet, las redes sociales y Whatsapp se han creado grupos y por ahí intercambian información" $"$.

La clasificación periodística de las fuentes informativas no oficiales se ha elaborado tomando como referencia las que se citan más asiduamente en las noticias analizadas: propias (testimonios de los familiares, amigos, vecinos; observación propia y reservadas o confidenciales, testimonios de expertos y fotografías), protagonistas (autor, víctima y testigos directos) y medios de comunicación. Los datos obtenidos en la tesis y en el estudio 2016 señalan que (en el ámbito no oficial) son las fuentes propias las más utilizadas por el periodista de sucesos, mientras que las provenientes de los protagonistas y los medios de comunicación son más minoritarias.

\subsection{Propias}

Son una de las fuentes más importantes del periodismo de sucesos que se nutre del trabajo propio que desarrolla el reportero en la calle, a través de los testimonios que recaba de

11 Estos grupos no sólo están integrados por reporteros, sino también por paramédicos, oficiales de la Policía Preventiva, Bomberos, personal de Protección Civil de diferentes dependencias e incluso directores de Gabinetes de Comunicación (las áreas de Comunicación Social) para proporcionar información extraoficial de lo que suceda. 
los familiares, amigos y conocidos de los autores o las víctimas, así como de vecinos o mediante la observación propia en el lugar de los hechos o el escenario del crimen. También se engloban las fotografías como documento gráfico que complementa la información recabada y que en el periodismo de sucesos es fundamental. Las fuentes propias se basan en la investigación que realiza el periodista, el cual consigue la información en bruto y la elabora.

La tipología de fuentes es diversa, ya que esta categoría se refiere a aquellas que no se pueden englobar en ninguna de las anteriores. Hay que aclarar que (aunque son las que presentan una mayor frecuencia de aparición dentro de las no oficiales) en el conjunto de todas las fuentes analizadas tienen una representatividad menor, pese a ser las más importantes y valoradas en la prensa. Es lógico si tenemos en cuenta que las oficiales y de agencias son las que se citan con mayor asiduidad en la prensa escrita. Estos datos son indicativos de que actualmente existe una excesiva dependencia de las fuentes oficiales y de las agencias de noticias, lo que tiende a uniformizar la información y la interpretación de los hechos.

Las fuentes propias más utilizadas son las reservadas o confidenciales y las procedentes de la observación propia, las familiares y las vecinales. Las menos citadas son las que tienen su origen en amigos y conocidos, los abogados y los expertos. En las fuentes reservadas o confidenciales existe la atribución a una fuente, pero el periodista no la revela. Es una práctica que suele emplearse cuando no es posible o conveniente identificar a la fuente informante. En este caso es habitual que los medios utilicen las siguientes expresiones: "según las fuentes consultadas por este periódico", "según los datos recabados", "según nuestras informaciones", "informaciones dignas de toda solvencia", "fuentes bien informadas" o "fuentes próximas a la investigación”. Es decir, se hace atribución a fuente anónima, puesto que se oculta.

La fuente familiar es un recurso que también se utiliza cuando es inviable obtener declaraciones del autor o la víctima del suceso, aunque en ocasiones pueda resultar inaccesible. Las fuentes vecinales son un recurso fácil que (a falta de declaraciones de los protagonistas o testigos directos) se emplea de comodín para elaborar la información. Sin embargo, son poco fiables, ya que suelen transmitir opiniones subjetivas, llenas de suposiciones, tópicos y generalizaciones. Por tanto, es una fuente accesible, pero de baja calidad por su escaso rigor.

Del conjunto de fotografías de sucesos publicadas en los cinco diarios analizados, las no oficiales son las más frecuentes y, dentro de estas, las mayoritarias son las realizadas por los fotógrafos o reporteros que trabajan o colaboran en estos periódicos. Además, las fotografías propias destacan especialmente, ya que se utilizan en los diarios en mayor número que las informaciones propias. Así lo pone de manifiesto el estudio 2016, que indica que de un total de 76 fuentes propias analizadas, 42 son fotos y 34 noticias. El recurso al pie de foto es común. 


\subsection{Protagonistas: autores, víctimas y testigos}

Son las fuentes más importantes del periodismo de sucesos, ya que se trata de los protagonistas de los sucesos: los autores, las víctimas y los testigos directos, según provenga la información del autor material o causante de los hechos, de la persona que sufre o padece el acto delictivo o el siniestro, y de otras personas que no son la parte afectada por el suceso, pero que han sido testigos presenciales. Se trata de un tipo de fuente personal y no oficial.

Es la fuente primaria por esencia del periodismo de sucesos y una de las más difíciles de conseguir, al ser información de primera mano de los protagonistas del suceso, sin depender de la versión de la nota oficial de la Policía o de otras fuentes institucionales que filtran los datos. Las declaraciones de los protagonistas, las imágenes captadas por los fotógrafos, los detalles sobre cómo han ocurrido los hechos según la versión de la víctima o del autor tienen un elevado interés informativo. Los periodistas consultados y especialistas en esta temática señalan que las fuentes no oficiales son las mejores, sobre todo, los testigos directos de los hechos y las víctimas y los autores, en el caso de que puedan ser entrevistados.

Las dos fuentes más difíciles de conseguir son las de las víctimas y los autores, siendo los testigos algo más asequibles. Los resultados de la tesis doctoral que tomamos de base así lo constatan, ya que dentro de la categoría de "fuente protagonistas", la víctima es la menos citada en los periódicos (por desgracia, se debe a que muchas de las personas que sufren o padecen el daño han muerto en un siniestro o han sido asesinadas). Las más mencionadas son la de los testigos, seguidas por los autores (el delincuente una vez detenido es complicado poder entrevistarlo). El estudio 2016 también coincide al reflejar que es una de las fuentes minoritarias del periodismo de sucesos. Es decir, la frecuencia de aparición de este tipo de fuente es, pese a su importancia, baja en la prensa escrita frente a las anteriores fuentes descritas.

\subsection{Medios de comunicación}

Son fuentes que utiliza el periodista cuando elabora una información de sucesos y cita a otro medio de comunicación (prensa, radio, televisión o digitales) para ampliar o complementar el desarrollo de su trabajo. Se trata de fuentes secundarias, ya que son informaciones que ya han sido elaboradas y difundidas por otros periodistas en la prensa, radio, televisión o medios digitales. No deja de ser una fuente de la competencia que se emplea como recurso informativo, sobre todo si se trata de sucesos imprevistos o de última hora emitidos en exclusiva por un determinado medio. La lógica rivalidad no excluye el hecho, por ejemplo, de que los periódicos se utilicen mutuamente como fuentes. Las páginas de sucesos analizadas ponen de manifiesto que es poco frecuente la utilización de este recurso.

Las redes sociales se han convertido en una nueva fuente de información cada vez más utilizada por los medios de comunicación. Ponemos varios ejemplos. El caso de 
delincuentes de los cuales los periodistas obtienen sus datos personales e imágenes a través de sus perfiles en Twitter o Facebook. Así ocurrió con el caso del "Pederasta de Ciudad Lineal" (Madrid), capturado el 24 de septiembre de 2014, cuyas fotos publicadas en su perfil de Facebook se difundieron en los medios. Y especialmente en el caso "Marta del Castillo" (desaparición y asesinato de una menor de 17 años en Sevilla, 2009), donde diversos medios utilizaron como principal fuente de información el perfil que esta joven tenía en Tuenti y los mensajes que se intercambiaba con los asesinos.

Este último caso hizo que las redes sociales entraran por primera vez en España dentro de la agenda mediática en relación con un acontecimiento de esta naturaleza ( $c f$. Herrero, 2013: 454). Un buen uso detectado es cuando un periódico consigue información complementaria en la red social (fuente secundaria) que posteriormente confirma acudiendo a una fuente primaria.

La utilización de fotos procedentes de otros medios de comunicación (para publicarlas en las páginas de sucesos de los diarios analizados en el estudio 2016) es reducida, aunque empieza a incrementarse a través de la captura de imágenes en la Internet o en las redes sociales.

\section{Agencias de noticias}

Es una de las fuentes principales de la que se nutre la prensa para difundir las informaciones de sucesos. Este dato lo corroboran tanto la tesis (constata que es la fuente más citada en los tres periódicos analizados) como el estudio 2016 (indica que es la segunda fuente más citada en los cinco periódicos), tal como se aprecia en el siguiente gráfico. Es EFE la agencia que con mayor frecuencia menciona la prensa (en un $69.76 \%$ de los casos), seguida a larga distancia por Europa Press.

Es recurrente el abuso de las fuentes provenientes de agencias. En la prensa escrita española se observa que una parte importante de las noticias de sucesos están elaboradas sobre la base de notas de agencia y de comunicados oficiales de la Policía.

Por tanto, este tipo de fuente tiene una gran influencia en el periodismo de sucesos, ya que es una de las que más se utiliza frente al resto de fuentes. Se trata de una fuente periodística secundaria porque suministra al resto de medios una información que ya ha sido previamente elaborada por otro profesional. La frecuente utilización de noticias de agencias para rellenar páginas de sucesos es un recurso fácil, pero poco recomendable en el quehacer periodístico. La información de agencia se puede emplear como fuente complementaria, pero no como recurso principal y habitual de método de trabajo ${ }^{12}$.

12 El buen periodista hace uso limitado de esta fuente porque prefiere, siempre que sea posible, publicar informaciones propias y utiliza el teletipo (que no deja de ser un trabajo hecho por otros compañeros) sólo como material de apoyo. Esta es la fórmula de diferenciación con respecto a los otros medios de la competencia: el dar noticias que otros no dan, las exclusivas que hay que trabajarse día a día en el periodismo de sucesos. 
Figura 3: Frecuencia de agencias citadas.

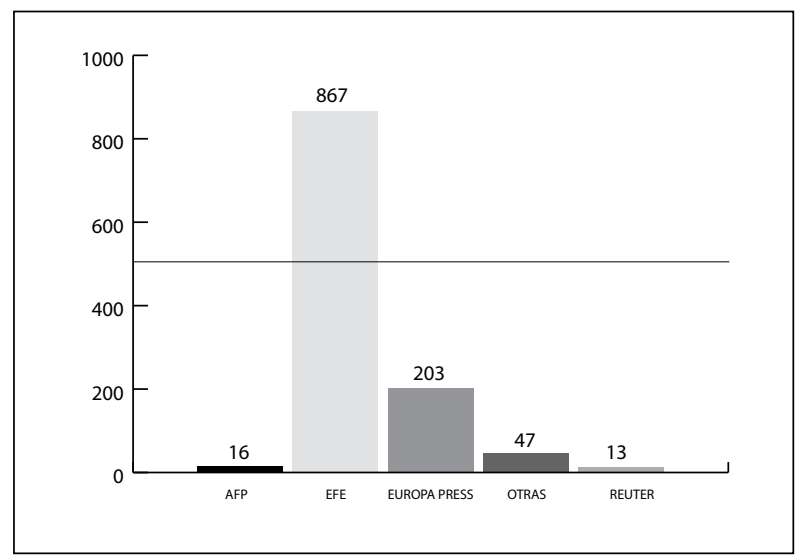

Fuente: Elaboración propia.

En la figura 3 se observa que la fuente de agencia más citada en la prensa escrita es $\mathrm{EFE}^{13}$, seguida a gran distancia de Europa Press ${ }^{14}$. Se trata de dos agencias españolas, la primera estatal y la segunda privada. Otras fuentes muy minoritarias que se citan son Reuter y AFP, en el caso de sucesos ocurridos en el extranjero.

La importancia de esta fuente es lógica, teniendo en cuenta que las agencias informativas proveen diariamente a los periódicos (impresos y digitales) de numerosas noticias de sucesos que sirven como complemento informativo de la actualidad diaria y, en ocasiones, como única fuente. Las plantillas de los periódicos españoles están cada vez más disminuidas por los continuos despidos, lo que genera una mayor dependencia de las notas oficiales y los teletipos de agencias.

La excesiva dependencia a las agencias repercute en la calidad de la información que se vuelve uniforme. Los periodistas comunican lo mismo y de la misma manera, ya que utilizan como fuente principal el texto elaborado por una agencia informativa. De ahí la importancia y la necesidad de tener periodistas especializados en esta temática, sabedores de la función clave que tienen las fuentes propias y exclusivas del medio como motores de un carácter único y especializado que marcan la posición que ocupa el periódico en la escala de valores y en la confianza del público.

13 Se crea en España en 1939. Según recoge en su página web, es la primera agencia de noticias en español y la cuarta del mundo. Distribuye casi 3 millones de noticias al año en los diferentes soportes informativos: texto, fotografía, audio, video y multimedia, que llegan diariamente a más de dos millares de medios de comunicación en el mundo. Más del 40\% de la información internacional de agencias publicada en América Latina es de EFE.

14 Fundada en Madrid en 1953. Difunde ininterrumpidamente más de tres mil informaciones diarias de carácter general y especializado, en formato texto y audiovisual. Europa Press tiene en su página electrónica, dentro de la sección de "Sociedad", una subsección de "Sucesos". 
En cuanto a la atribución de las noticias que proceden de las agencias, hemos detectado en el estudio 2016 que el $56.41 \%$ de las casos no se especifica el origen de la información y en un $43.58 \%$ sí. Más de la mitad de los teletipos no especifican su procedencia y en los cinco periódicos analizados se suelen reflejar genéricamente como "según recoge la agencia EFE" o "según fuentes de agencia".

Cuando se identifican las fuentes en las noticias de agencias publicadas, todas ellas son oficiales y dimanan en primer lugar del ámbito policial ("según informaron a Europa Press fuentes policiales", seguido del institucional ("según ha indicado a EFE el portavoz del hospital") y finalmente del judicial ("según han precisado a EFE fuentes judiciales"). Por tanto, entendemos que un elevado porcentaje de noticias de agencias se nutren de fuentes oficiales. En esta línea, otro estudio realizado por Mayoral (2005: 97) sobre el uso periodístico de las fuentes de información, menciona que un $30 \%$ de las fuentes de agencias remiten a fuentes oficiales.

Hemos visto que las fotos de sucesos que tienen su origen en fuentes no oficiales (sobre todo las realizadas por los propios periódicos y de forma mucho más minoritaria las que provienen de otros medios), son las más abundantes en la prensa escrita. A continuación, por un estrecho margen le siguen las fotos de agencias que se publican en los periódicos para ilustrar noticias de sucesos. Como vemos, la agencia es también una fuente relevante en el periodismo de sucesos como suministradora de imágenes gráficas. En el estudio 2016 se refleja que la prensa escrita selecciona con mayor frecuencia fotos que noticias de teletipos: de las 84 fuentes informativas de agencias, el $53.57 \%$ son fotos y el $46.42 \%$ información textual.

\section{Fuentes indeterminadas}

Son aquellas en las que no constan fuentes en las informaciones de sucesos que se publican, aunque evidentemente los periodistas las hayan utilizado para redactar las noticias. La atribución de la fuente se desconoce no porque sea confidencial, sino porque simplemente el reportero no la refleja. En este sentido, partimos de la base de que, como norma general,

"toda información debe mencionar las fuentes en las que se basa, excepto cuando en la comprobación personal de los sucesos descritos por el periodista quede implícita o sea necesario el anonimato o preservar la confidencialidad de la fuente" (Rodríguez, 2015: 97).

La práctica de publicar noticias que no presentan ningún tipo de atribución a fuentes se reitera en informaciones cortas (sueltos o breves), que van sin firmar y donde sólo se ofrecen los datos básicos del suceso, sin analizar el cómo y porqué de los hechos, lo que conlleva no citar la procedencia por falta de espacio. La fuente originaria suele provenir de comunicados policiales o de informaciones de agencias que se resumen y publican sin más comprobación. No existe atribución, puesto que no constan. 
Los resultados de ambos estudios ponen de manifiesto que las fuentes con atribución son las mayoritarias, aunque aparecen insuficientemente identificadas. El resto de noticias de sucesos que se publican son indeterminadas. En concreto, en la tesis se constata que en el $72.17 \%$ de las fuentes citadas hay atribución y en un $27.82 \%$ no existe atribución (no se cita fuente alguna). El estudio 2016 refleja que en un $86.66 \%$ de los caso se citan con atribución y en un $13.33 \%$ sin atribución.

\section{Conclusiones}

Si se toma como referencia los datos recabados de la tesis, se pone de manifiesto que las fuentes más citadas provienen de las agencias de noticias $(32.50 \%)$ y de las oficiales (29.80\%), seguidas por las no oficiales (10.74\%). En el caso del estudio 2016, el resultado indica que la oficial es la más citada por los periodistas en los diarios analizados (un $41.90 \%$ ). Después les siguen las no oficiales $(26.19 \%)$ y las de agencias $(18.33 \%)$. El porcentaje de las noticias de sucesos donde no se cita ninguna fuente (indeterminadas) es del $27.82 \%$ (tesis) y del $13.33 \%$ (estudio 2016).

Ambos estudios indican que prevalecen mayoritariamente en las noticias de sucesos analizadas las fuentes oficiales frente a las no oficiales ${ }^{15}$. En el caso de la tesis, las oficiales suponen un $29.80 \%$ de frecuencia y las no oficiales un $10.49 \%$. Por su parte, el estudio 2016 señala que $41.90 \%$ son oficiales frente a un $26.19 \%$ no oficiales. No obstante, son datos relativos, ya que hay que tener en cuenta que cerca más de un $40 \%$ de las informaciones facilitadas por las agencias tienen su origen en fuentes oficiales. En el caso de las fuentes indeterminadas, como no consta su origen, no reflejan si son oficiales o no oficiales.

Según se deduce en la tesis, las fuentes oficiales mayoritarias son las policiales, seguidas de las gubernamentales. Por su parte, los datos del estudio 2016 indican que las más citadas son las que tienen su origen en las autoridades de gobierno y después las de la Policía. Se constata en ambos análisis el mayor protagonismo que están adquiriendo las fuentes institucionales provenientes de las autoridades, siendo las más citadas en los periódicos las del ámbito estatal, municipal y regional, por este orden. También se pone de manifiesto la importancia de la institución policial como fuente especializada que nutre a la prensa escrita y a las agencias informativas (hemos detectado que la mayoría de sus fuentes oficiales emanan de la Policía).

Con respecto a las fuentes no oficiales, los datos muestran que las fuentes propias son las que tienen mayor reflejo en la prensa, seguidas a continuación por las declaraciones de los protagonistas de los sucesos y las conseguidas en otros medios de comunicación. Dentro de las propias, son las fuentes reservadas o confidenciales (se suelen citar genéricamente como "según las fuentes consultadas"), las familiares y las vecinales las mayoritariamente

15 No se han computado ni las fuentes provenientes de agencias ni las indeterminadas. 
usadas en prensa. Del conjunto de fuentes analizadas en la tesis, representan sólo un $6.18 \%$, mientras que en el estudio 2016 suponen un $16.1 \%$.

La atribución pone de manifiesto cómo usan los periodistas las fuentes de información: si se atribuyen de forma concreta, reservada o simplemente no se atribuyen. En las noticias de sucesos mayoritariamente se atribuyen las fuentes, aunque es común que no se identifiquen de forma concreta, sino genérica. Los periodistas emplean un elevado número de fuentes atribuidas, pero insuficientemente identificadas ("según fuentes policiales", "según han confirmado fuentes hospitalarias", "fuentes oficiales han informado") y, en menor número, fuentes atribuidas de carácter reservado o confidencial ("según las fuentes consultadas por $E l$ Mundo", "según ha podido saber $A B C$ de fuentes cercanas al caso", "fuentes del caso han informado", "según ha podido saber este periódico de fuentes bien informadas").

La frecuencia de noticias que tienen atribución confidencial o reservada (se atribuye de forma anónima) es minoritaria (un 3\% aproximadamente). Entendemos que el periodista utiliza este recurso, donde se hace una deficiente atribución informativa, porque tiene que preservar sus fuentes y el anonimato de los confidentes. Gran parte de este tipo de fuentes provienen de los contactos que el periodista tiene, pero que no puede revelar, ya sean del ámbito policial, judicial o de personas próximas a las víctimas o los autores. Por tanto, las fuentes con atribución son las mayoritarias (siendo las menos frecuentes las reservadas o confidenciales), seguidas de las que no consta atribución (indeterminadas).

Del estudio 2016 se evidencia la importancia cada vez mayor de las fuentes fotográficas en la prensa escrita. Las fuentes textuales (información) son más numerosas que las fotográficas, ya que total de las 315 fuentes computadas en los 263 registros informativos analizados, 210 son noticias y 105 fotos. Las fotografías de sucesos tienen una representatividad en los diarios analizados del $33.33 \%$. De este porcentaje, las fotografías que ilustran las páginas de sucesos de los diarios proceden, en primer lugar, de las no oficiales, seguidas de las de agencias y, en tercer lugar, de las facilitadas por la Policía.

Con respecto a las fuentes no oficiales, las fotos publicadas han sido realizadas fundamentalmente por fotógrafos de los periódicos analizados (fuentes propias) y son minoritarias las que se insertan recogidas otros medios de comunicación. En cuanto a las agencias, es significativo señalar que en los cinco periódicos analizados se utilizan, en mayor número, las fuentes fotográficas (45) que las suministradas en formato texto (39). Las fotos que aparecen en los periódicos de fuentes oficiales sólo provienen de la Policía y son minoritarias en comparación con las anteriores. Ello se debe a que las fuentes oficiales suministran fundamentalmente información textual a través de comunicados, notas de prensa o portavoces. 


\section{Fuentes consultadas}

Agencia EFE (2016). “Edición España”. Extraída el 5/VII/2016 desde http://www.efe.com/efe/espana/1

Agencia Europa Press (2016). "Europa Press”. Extraída el 5/VII/2016 desde www.europapress.es

Arias, J. (2014, mayo 16). Redactor del semanario de sucesos El Caso en la década de 1980. Entrevista personal. Sevilla, España.

Ballesteros, J. (2008, mayo 12). Periodista especializado en sucesos en el desaparecido periódico Diario 16 Andalucía. Sevilla, España.

Cambón, A. (2008, mayo 28). Portavoz policial del Gabinete de Prensa de la Jefatura Superior de Policía de Andalucía Occidental. Entrevista telefónica y cuestionario contestado por escrito. Sevilla, España.

Diezhandino, M. y Coca, C. (1997). La nueva información. Bilbao: Servicio Editorial de la UPV.

El Informador (2016). "El Informador - Portada principal”. Extraída el 5/VII/2016 desde www.elinformador.com.ve

Fernández Muñoz, C. (2014, mayo 21). Periodista especializado en información de sucesos en diversos periódicos de Cádiz. Entrevista personal. Sevilla, España.

Guardia Civil del Gobierno de España (2016). "Guardia Civil - Portada principal". Extraída el 5/VII/2016 desde www.guardiacivil.es

Herrero Curiel, E (2013). "Fuentes periodísticas y redes sociales en las noticias de Marta del Castillo”. Estudios sobre el Mensaje Periodístico, vol. 19, núm. 1, pp. 453-469.

Junta de Andalucía (2016). "Portal de la Junta de Andalucía". Extraída el 5/VII/2016 desde www.juntadeandalucia.es

Mayoral Sánchez, J. (2005). "Fuentes de información y credibilidad periodística". Estudios sobre el Mensaje Periodístico, vol. 11, pp. 93-102.

Ministerio de Justicia del Gobierno de España (2016). "Ministerio de Justicia - Portada principal”. Extraída el 5/VII/2016 desde www.mjusticia.gob.es

Ministerio del Interior del Gobierno de España (2016). "Ministerio del Interior - Portada principal”. Extraída el 5/VII/2016 desde www.interior.gob.es 
Ochoa Tirado, H. (2016, febrero 22). Reportero mexicano especializado en la nota roja (policía, procuración e impartición de justicia). Datos facilitados por correo electrónico. Ciudad de México, México.

Orden INT/28/2013, de 18 de enero, por la que se desarrolla la estructura orgánica y funciones de los Servicios Centrales y Periféricos de la Dirección General de la Policía, artículo 1. BOE núm. 21 (24/I/2013).

Pérez Ávila, F. (2014, julio). Periodista de sucesos del Diario de Sevilla. Entrevista telefónica. Sevilla, España.

Policía Nacional del Gobierno de España (2016). "Policía Nacional - Portada principal". Extraída el 5/VII/2016 desde www.policia.es

Portavoz Oficial de la Guardia Civil (2014, julio 24). Representante oficial de la Oficina Periférica de Comunicación (OPC). Entrevista telefónica y cuestionario remitido por correo electrónico. Sevilla, España.

Quesada, M. (2007). Periodismo de sucesos. Madrid: Síntesis.

Rodríguez, C. (2014, junio 15). Periodista local de sucesos de El Mundo (edición Andalucía). Entrevista telefónica y cuestionario contestado por escrito. Sevilla, España.

\section{Rodríguez Carcela, $\mathbf{R}$.}

_(2015). Manual de periodismo de sucesos. Sevilla: Laboratorio de Estudios en Comunicación, Grupo de Investigación en Estructura, Historia y Contenidos de la Comunicación.

_(2009). La información de sucesos en la prensa escrita. Sevilla: Universidad de Sevilla.

Ronda, J. y Calero, J. (2000). Manual de periodismo judicial. Sevilla: Grupo de Investigación en Estructura, Historia y Contenidos de Comunicación.

Torres, S. y Salvador, A. (2015). El saqueo de los ERE. Salamanca: Libros.com. 